\title{
Comparação da germinação e crescimento de sementes após aplicação de lodo de Estação de Tratamento de Esgoto (ETE) e fertilizante químico.
}

\section{Beatriz F. Nunes, Maraline C.K. Zanatta, e Marta S. G. Pires.}

\section{Resumo}

O número de municípios no Brasil que não tem seu esgoto tratado é muito grande. Apesar do défict em relação ao tratamento de esgotos como resultado desse tratamento é gerado grande quantidade de lodo de esgoto, que não pode ser descartado no ambiente de qualquer maneira pois pode causar impactos ambientais negativos devido a sua composição. Existem várias formas de reaproveitamento de lodo e por se tratar de um material com grande quantidade de matéria orgânica o mesmo apresenta um grande potencial agrícola, e se usado em determinadas concentrações pode favorecer a fertilidade solo. O objetivo desse projeto de Iniciação Cientifica é analisar o desenvolvimento de sementes de nabo (Brassica rapa) e repolho (Brassica oleracea) após aplicação de lodo de esgoto bruto, lodo de esgoto tratado e fertilizante químico em diferentes concentrações.

\section{Palavras-chave:}

Lodo de esgoto, desenvolvimento de sementes, reaproveitamento de resíduo.

\section{Introdução}

O solo ao receber aplicação de lodo de esgoto pode apresentar melhorias nas propriedades como porosidade, estabilidade de agregados, capacidade de retenção de água, aumento da matéria orgânica, além de ser interessante do ponto de vista econômico e ambiental. (GONZAGA et al., 2017; HÉRNANDEZ et al., 2016).

Uma forma de avaliar o efeito do lodo aplicado ao solo é utilizando testes de fitotoxicidade recomendados para estimar os riscos da aplicação desse resíduo e tem sido recomendado pela EPA. (NAFEZ et al., 2015).

Um dos objetivos do projeto é verificar se existe diferença de sensibilidade entre as sementes utilizadas e comparar a efetividade do desenvolvimento das sementes em relação ao uso de fertilizante e ao uso de lodo de esgoto.

\section{Resultados e Discussão}

Em relação ao teste de sementes os resultados foram avaliados de acordo com os critérios estabelecidos por Tam \& Taquia (1994), determinando-se a germinação relativa das sementes, alongamento relativo das raízes e índice de germinação.

As concentrações de CE50 para as sementes de nabo e repolho respectivamente foram: 0 dias, 32,7 e 23,6; 30 dias, 46,16 e 25; e 90 dias, 48,8 e 43,37

Figura 1 - Resultados obtidos para alongamento relativo das raízes de nabo e repolho aplicando-se fertilizante químico.

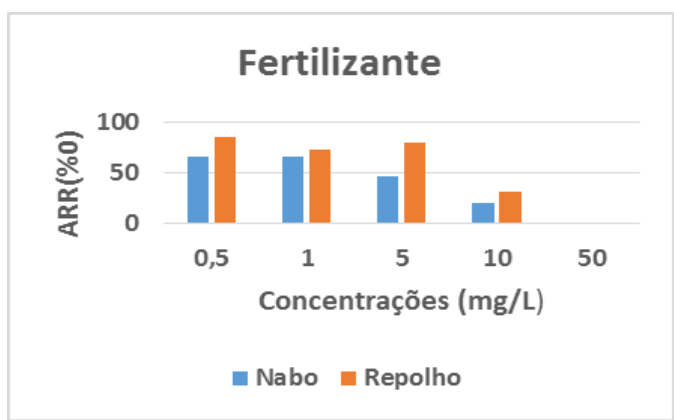

Fonte: Autoria própria/ Junho 2019.
Figura 2 - Resultados obridos para alonamento relativo das raízes de nabo e repolho aplicando-se lodo de esgoto em função do tempo.

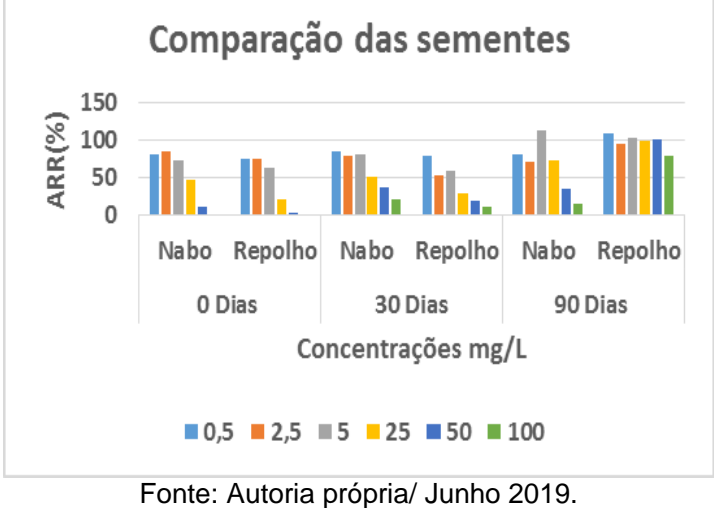

\section{Conclusões}

Analisando os valores de CE50 ao longo do tempo e observando-se a Figura 2, pode-se concluir que a toxicidade do lodo de esgoto tanto para as sementes de Brassica rapa (nabo), quanto para as sementes de Brassica oleracea (repolho) foi diminuindo. Conforme o lodo foi se estabilizando pode-se aplicar nas sementes uma maior concentração de lodo de modo que não afetasse de maneira negativa seu crescimento e desenvolvimento. Para a semente de nabo não foi observada toxicidade após 60 dias de estabilização do lodo.

GONZAGA, M.I.S.; MACKOWIAK, C.L.; COMERFORD, N.B.; MOLINE, E.F.V.; SHIRLEY, J.P.; GUIMARAES, D.V. Pyrolysis methods impact biosolids-derived biochar composition, maize growth and nutrition. Soil \& Tillage Research 165 (2017) 59-65

HERNÁNDEZ, T.; CHOCANO, C.; MORENO, J.L.; GARCÍA, C. Use of compost as an alternative to conventional inorganic fertilizers in intensive lettuce (Lactuca sativa L.) crops- Effects on soil and plant. Soil \& Tillage Research 160 (2016) 14-22.

NAFEZ, A.H.; NIKAEEN, M.; KADKHODAIE, S.; HATAMZADEH, M.; MOGHIM,S. Sewage sludge composting: quality assessment for agricultural application Environ. Monit. Assess. (2015) 187: 709.

TAM, N.F.Y; TIQUIA. S.M Assesing toxity of 'spent sawdust pig-litter' using seed germination technique. Resource Conservation Recycling, v.11,P.261-274, 1994 